\title{
Analisis Gap Pada Metode Pembelajaran Berbasis Elektronik Terstruktur dan Tidak Terstruktur Untuk Mengetahui Tingkat Keberhasilan Penyampaian Materi Kuliah Kepada Mahasiswa
}

\author{
Mauladia $^{\mathrm{a} 1}$, Rizqa Raaiqa Bintana ${ }^{\mathrm{a} 2}$, Benedika Ferdian Hutabarat ${ }^{\mathrm{a} 3}$ \\ ${ }^{a}$ Program Studi Sistem Informasi, Universitas Jambi \\ Jl. Raya Jambi-Muara Bulian KM. 15 Mendalo Indah, Muaro Jambi, Jambi \\ ${ }^{1}$ mauladi@unja.ac.id \\ 2rizqa.raaiqa.bintana@unja.ac.id \\ 3benedika@unja.ac.id
}

\begin{abstract}
Abstrak
Perkembangan Teknologi Informasi telah mendorong kemajuan di berbagai bidang. Dalam bidang pendidikan, contohnya penggunaan e-learning yang merupakan hasil integrasi teknologi dan pendidikan yang muncul sebagai media untuk pembelajaran yang menggunakan teknologi internet. Kebutuhan e-learning yang tak terbantahkan dalam pendidikan menyebabkan pertumbuhan yang besar dalam hal jumlah materi e-learning yang di-share dan sistem e-learning yang menawarkan berbagai jenis layanan. Ada 2 tipe e-learning, yaitu unstructured e-learning dan structured e-learning. Masing-masing tipe tersebut dibedakan menjadi dua bentuk berdasarkan faktor-faktor evaluasi kesuksesan suatu e-learning. Pesatnya penggunaan $e$-learning sebagai media pembelajaran, membuat kualitas sistem e-learning menjadi perhatian besar untuk memaksimalkan efektivitas sistem e-learning. Evaluasi kualitas sistem e-learning menjadi sangat penting dilakukan untuk memastikan dan mengetahui tingkat keberhasilan penyampaian materi melalui e-learning kepada para peserta didik, penggunaan $e$-learning yang efektif, dan dampak positif e-learning untuk peserta didik. Dua metode pembelajaran berbasis $e$ learning yang dilakukan, yaitu structured learning dengan user interface baik dan unstructured learning dengan user interface baik. Evaluasi dilakukan terhadap penyajian mata kuliah dengan dua metode pembelajaran berdasarkan hasil tes pemahaman materi. Hal ini dilakukan untuk melihat bagaimana pemahaman mahasiswa terhadap materi mata kuliah yang dibedakan atas dua kategori penyajian. Serta melakukan evaluasi kegunaan (usability) produk LMS UNJA. Diperoleh nilai rata-rata test akhir 78,15 untuk metode structured learning dan 69,19 untuk metode unstructured learning. Hasil evaluasi usability produk LMS UNJA, menyatakan secara keseluruhan, produk LMS UNJA secara usability sudah dapat diterima atau sudah layak, sesuai dengan rata-rata nilai usability produk yang diperoleh yaitu, 73,46.
\end{abstract}

Kata kunci: e-learning, evaluasi, kualitas, structured e-learning, unstructured e-learning

\section{Gap Analysis on Structured and Unstructured Electronic Learning Methods to Determine the Success Rate of Delivering Course Material to Students}

\begin{abstract}
The development of Information Technology has driven progress in various fields. In the field of education, for example, the use of e-learning is the result of the integration of technology and education which has emerged as a medium for learning using internet technology. The undeniable need for e-learning in education has led to great growth in the number of e-learning materials being shared and e-learning systems offering a wide variety of services. There are 2 types of e-learning, namely unstructured e-learning and structured e-learning. Each of these types is divided into two forms based on the success evaluation factors of e-learning. The rapid use of elearning as a learning medium has made the quality of the e-learning system a great concern to maximize the effectiveness of the e-learning system. Evaluation of the quality of the e-learning system is very important to do to ensure and determine the success rate of delivery of material through e-learning to students, the effective use of e-learning, and the positive impact of e-learning for students. Two e-learning-based learning methods are used, namely structured learning with a good user interface and unstructured learning with a good user interface. Evaluation is carried out on the presentation of courses with two learning methods based on the
\end{abstract}


results of the material understanding test. This is done to see how students understanding of the subject matter is divided into two categories of presentation. As well as evaluating the usability of LMS UNJA products. Obtained an average score for the final test 78.15 for the structured learning method and 69.19 for the unstructured learning method. The results of the usability evaluation of LMS UNJA products stated that overall, the usability LMS products were acceptable or feasible, following by the average usability value of the products obtained, namely, 73.46 .

Keywords: e-learning, evaluation, quality, structured e-learning, unstructured e-learning

\section{Pendahuluan}

Perkembangan Teknologi Informasi telah mendorong kemajuan di berbagai bidang seperti keuangan, bisnis, kesehatan, dan pendidikan. Dalam bidang pendidikan, hingga saat ini berkembang pesat, contohnya penggunaan e-learning yang merupakan hasil integrasi teknologi dan pendidikan yang muncul sebagai media untuk pembelajaran yang menggunakan teknologi internet. Sejak tahun 1960-an, e-learning telah terlibat dalam berbagai hal dalam bisnis, pendidikan, bidang pelatihan, dan militer. Dalam bidang pendidikan, e-learning mengacu pada penggunaan perangkat lunak dan pembelajaran online, sedangkan dalam bisnis, militer dan pelatihan, e-learning mengacu hanya pada seputar praktik/latihan yang bersifat online [1][2][3].

Pembelajaran yang dahulu hanya bisa dilakukan dengan cara konvensional (tatap muka), sekarang sudah dapat dilakukan dengan bantuan media lain, salah satunya dengan cara teknologi pemrograman yang diaplikasikan ke dalam e-learning. E-learning adalah sebuah proses pembelajaran yang berbasis elektronik dengan media yang digunakan adalah internet, jaringan komputer maupun komputer standalone [4]. Contoh penerapan e-learning dalam instansi pendidikan dapat dilihat melalui berbagai universitas yang menyediakan fasilitas e-learning, juga beberapa pendidikan non-formal. Fasilitas e-learning memungkinkan terjadinya pembelajaran jarak jauh atau lebih tepatnya sistem e-course (kuliah jarak jauh). Dengan e-learning, pembelajaran dapat dilakukan kapan saja dan di mana saja, serta menjangkau wilayah geografis yang lebih luas. Seseorang yang tidak dapat mengikuti pendidikan konvensional atau pendidikan resmi, tetap bisa belajar dan memperoleh materi melalui e-learning [5]. Peserta e-learning dapat secara fleksibel mengelola kegiatan pembelajaran sesuai dengan waktu dan aktivitas lain sehari-hari.

Kebutuhan e-learning yang tak terbantahkan dalam pendidikan menyebabkan pertumbuhan yang besar dalam hal jumlah materi e-learning yang di-share dan sistem elearning yang menawarkan berbagai jenis layanan [6][5]. E-learning sudah menjadi arus utama di bidang pendidikan dan telah diadopsi secara besar-besaran di pendidikan yang lebih tinggi atau universitas. Lembaga pendidikan tinggi telah mengadopsi LMS (Learning Management System) untuk mendukung layanan pendidikan.

Ada 2 tipe e-learning, yaitu unstructured elearning dan structured e-learning. Unstructured e-learning artinya cara belajar yang tidak terstruktur/tidak berjenjang, tidak termanajemen secara sistem, tidak ada evaluasi pembelajaran melalui sistem, tetapi proses learning (pembelajaran) terjadi. Contoh unstructured elearning, yaitu udemy.com, ruangguru.com, youtube.com, lynda.com, dan google.com. Sedangkan structured e-learning, konten e-learning dikelola secara sistem sehingga cara belajar menjadi terstruktur, melibatkan manajemen pembelajaran, ada kontrol untuk kehadiran, partisipasi, hak dan wewenang peserta, pembelajaran terikat dengan waktu, dan adanya evaluasi pembelajaran. Contoh structured e-learning, yaitu coursera.org, edx.org, dan campus MOOC (Massive Open Online Courses).

Pesatnya penggunaan e-learning sebagai media pembelajaran yang tak terbatas ruang dan waktu di saat ini, membuat kualitas sistem e-learning pada perguruan tinggi atau universitas menjadi perhatian besar bagi para peneliti dan peneliti telah berusaha mengidentifikasi faktor-faktor kesuksesan e-learning untuk memaksimalkan efektivitas sistem e-learning. Evaluasi kualitas sistem e-learning menjadi sangat penting dilakukan untuk memastikan dan mengetahui tingkat keberhasilan penyampaian materi melalui $e$ - learning kepada para peserta didik, penggunaan e-learning yang efektif, dan dampak positif e-learning untuk peserta didik. Penelitian yang dilakukan oleh Al-Fraihat et al. (2020) melakukan evaluasi kualitas sistem e-learning untuk dengan beberapa penilaian dasar, yaitu UI (user interface), penyajian konten, speed (kecepatan internet), log (record aktivitas pengguna e-learning), dan ketersediaan konten video dalam materi pembelajaran [6][7]. Dari hasil evaluasi tersebut diketahui terdapat gap pada masing-masing bentuk e-learning (structured dan unstructured). Pada penelitian yang dilakukan kali ini adalah mengetahui hasil penilaian pre-test dan post-test mahasiswa yang mengambil dua mata kuliah berbeda dengan dua bentuk pembelajaran yang berbeda pada learning management system (LMS) dan mengevaluasi LMS tersebut.

\subsection{E-Learning}

E-learning bisa dinyatakan dengan istilah lain seperti kursus/pembelajaran online, pembelajaran berbasis web, pelatihan berbasis web, objek pembelajaran atau pembelajaran jarak jauh. Semua bentuk e-learning, apakah itu sebagai aplikasi, program, objek, situs web, maupun lainnya, pada akhirnya memberikan kesempatan belajar bagi individu [4]. Kata kunci dari e-learning adalah penggunaan teknologi untuk tujuan pembelajaran, pengetahuan, dan pengembangan keterampilan. Aspek- 
aspek penting dari konsep e-learning seperti didistribusikan (ilmu dan pengetahuan), fleksibel, kapan saja dan interaktivitas [8][3].

E-learning telah berkembang pesat dengan berbagai teknologi dan perangkat untuk mengakses sumber belajar, seperti laptop, komputer, smartphone, dan tablet. Teknologi telah sangat mempengaruhi pendidikan, pembelajaran, dan metode pengajaran. Secara tradisional, aksesibilitas ke materi pembelajaran telah terbatas pada beberapa individu. Kolaborasi dan komunikasi juga terbatas pada siswa di kelas yang sama. Saat ini, sejumlah besar sumber daya pembelajaran dalam berbagai format (misalkan, teks, gambar, audio, dan video) tersedia melalui internet yang mendorong pembelajaran mandiri dan melampaui batas-batas geografis [9][7]. E-learning sebagai sistem informasi yang dapat mengintegrasikan berbagai bahan ajar (melalui audio, video, dan media teks) yang disampaikan melalui e-mail, sesi obrolan langsung, diskusi online, forum, kuis, dan tugas. Peneliti lain menggunakan konsep $e$ - learning untuk merujuk pada intervensi teknologi dalam proses pembelajaran [6].

Instruktur bertanggung jawab atas motivasi dan otonomi peserta didik, memastikan keberhasilan penyampaian materi ke peserta didik. Desainer sistem $e$ learning bersama dengan stakeholder lainnya bertanggung jawab atas interaktivitas dalam pembelajaran melalui mediasi teknologi untuk keberhasilan e-learning [10]. Kustomisasi materi pembelajaran, desain materi pembelajaran yang tepat, teknologi dan interoperabilitas desain dan desain antarmuka yang akurat dipahami sebagai tanggung jawab utama para desainer sistem $e$ learning. Ketersediaan teknologi yang diperbarui (teknologi handal), desain materi pembelajaran yang tepat dan kepemimpinan yang menghargai pembelajaran digital adalah faktor utama keberhasilan untuk menyampaikan pembelajaran pada platform digital dengan kemudahan penggunaan dan otonomi untuk pelajar di era saat ini. Oleh karena itu, jelas bahwa kolaborasi para pemangku kepentingan dalam suatu organisasi adalah kunci untuk $e$ learning yang efektif [11].

Pada e-learning terdapat dua jenis pembelajaran, structured (terstruktur) dan unstructured (tak terstruktur). Untuk metode pembelajaran terstruktur, diterapkan skenario dalam penyajian konten mata kuliah sehingga tercapai pembelajaran yang termanajemen secara terstruktur. Bentuk skenario yang diterapkan dalam proses pembelajaran terstruktur menyesuaikan dengan kebutuhan pengajar. Sedangkan untuk metode pembelajaran tidak terstruktur, tidak diterapkan skenario dalam penyajian konten mata kuliah seperti yang dilakukan dalam pembelajaran terstruktur, sehingga peserta bisa mengakses materi secara acak dan tidak terurut.

\subsection{Learning Management System}

Learning Management System merupakan sebuah platform e-learning, yang menyediakan konten pembelajaran dan sumber informasi antara siswa dan guru, mahasiswa dan dosen, maupun instruktur (tutor) dan peserta didik. LMS memainkan peran sentral dalam skenario e-learning berbasis web yang dapat diakses kapan saja dan dimana saja. LMS menghubungkan isi pembelajaran dan peserta didik bersama-sama dalam cara yang standar [12]. LMS mengelola pengguna, materi pembelajaran (dalam bentuk objek dalam Content Management System) dan kegiatan pembelajaran. LMS mengatur dan mengelola perkembangan kegiatan pembelajaran dan melacak kinerja kegiatan pembelajaran. LMS juga mengatur dan mengelola tugas-tugas administrasi. LMS adalah sistem perangkat lunak yang dirancang untuk memfasilitasi tugas-tugas administrasi serta partisipasi siswa/peserta didik dalam materi $e$ learning [13].

\subsection{System Usability Scale}

SUS adalah salah satu metode evaluasi yang digunakan dalam rangka untuk melihat usabilitas dari sebuah produk perangkat lunak (contoh: aplikasi, website). SUS juga dapat digunakan untuk melihat tingkat penerimaan seseorang terhadap teknologi pembelajaran [14][15].

\section{Metodologi}

\subsection{Waktu dan Tempat}

Penelitian dilaksanakan di Fakultas Sains dan Teknologi Universitas Jambi yang beralamatkan di Jl. Raya Jambi, Ma. Bulian KM. 15 Mendalo Indah, Jambi. Waktu penelitian yaitu bulan Juli-November 2020.

\subsection{Rancangan Penelitian}

Peserta atau objek penelitian ini adalah mahasiswa Program Studi Sistem Informasi Fakultas Sains dan Teknologi Universitas Jambi angkatan 2020 sebanyak 35 orang dimana partisipan dalam penelitian ini belum pernah mengikuti mata kuliah yang diujikan sebelumnya. Mata kuliah yang dipilih dalam pelaksanaan penelitian ini yaitu mata kuliah Pemrograman WEB Dasar untuk metode Structured learning (tanpa gap) dan Basis Data untuk metode Unstructured Learning (tanpa gap). Mata kuliah yan telah dipilih akan diberikan secara daring kedalam LMS-UNJA untuk dilihat efektifitas penggunaan e-learning tersebut serta membandingkan capaian pengetahuan mahasiswa dengan dua metode pembelajaran secara elektronik Structured learning (tanpa gap) dan Unstructured Learning (tanpa gap). Evaluasi pembelajaran dilakukan dengan menggunakan nilai pretest dan post-test yang diberikan pada partisipan untuk menganalisis capaian pembelajaran mata kuliah yang telah ditentukan.

Dalam uji coba penelitian, dibuat dua buah kelas, dimana masing-masing kelas diberikan materi pembelajaran mulai dari topik 1 hingga topik 5 (5 kali pertemuan). Dua mata kuliah tersebut adalah mata kuliah Pemrograman Web Dasar dan Basis Data I. Metode structured learning dengan UI baik diterapkan ke dalam kelas Pemrograman Web Dasar sesuai skenario yang dibuat oleh peneliti. Sedangkan metode unstructured learning dengan UI baik diterapkan ke dalam kelas Basis Data I. 


\subsection{Analisa Data}

Efektivitas penggunaan E-learning terhadap kegiatan pembelajaran dilakukan dengan menggunakan pengujian SUS (System Usability Scale). Sedangkan evaluasi hasil pembelajaran dari masing-masing metode dilakukan dengan membandingkan nilai pre-test dan post-test dari masing-masing kelompok dan dianalisis secara deskriptif kuantitatif dan data disajikan dalam bentuk tabulasi dan grafik.

\section{HASIL DAN PEMBAHASAN}

Dua metode pembelajaran berbasis e-learning yang dilakukan, yaitu structured learning dengan UI baik dan unstructured learning dengan UI baik. Pemilihan sampel penelitian, yaitu melibatkan mahasiswa Program Studi Sistem Informasi FST UNJA Angkatan 2019 dan 2020.

Structured learning atau pembelajaran terstruktur, artinya konten pembelajaran (dalam penyajiannya) dimanajemen secara terstruktur sehingga cara belajar menjadi terstruktur, melibatkan manajemen pembelajaran, ada kontrol untuk kehadiran, partisipasi, hak dan wewenang peserta didik (mahasiswa), pembelajaran terikat dengan waktu, adanya evaluasi pembelajaran, dan kontrol kualitas. Unstructured learning atau pembelajaran tidak terstruktur, artinya cara belajar yang tidak terstruktur / tidak berjenjang, tidak termanajemen secara terstruktur, tidak ada evaluasi pembelajaran, tetapi proses learning (pembelajaran) terjadi, peserta didik bisa mengakses materi secara acak menyesuaikan dengan kebutuhannya, tidak harus diakses secara terurut.

\section{A. Scenario Penyajian Konten Pembelajaran}

Berikut adalah skenario yang penulis terapkan dalam metode structured learning dengan UI baik dan bentuk kegiatan unstructured learning dengan UI baik.

TABEL I

SKENARIO PENYAJIAN KONTEN MATA KULIAH DALAM METODE STRUCTURED LEARNING DENGAN UI BAIK

\begin{tabular}{|c|l|}
\hline No & \multicolumn{1}{c|}{ Skenario } \\
\hline 1 & $\begin{array}{l}\text { Pengajar memberikan deskripsi mata kuliah dan topik-topik } \\
\text { pembahasannya di halaman pembuka kelas e-learning. }\end{array}$ \\
\hline 2 & $\begin{array}{l}\text { Pengajar menyediakan menu Pilih Kelas di kelas e-learning } \\
\text { agar mahasiswa memilih kelas mereka masing-masing di } \\
\text { pertemuan pertama perkuliahan. }\end{array}$ \\
\hline 3 & $\begin{array}{l}\text { Pengajar menyediakan menu Presensi Kelas untuk masing- } \\
\text { masing kelas sehingga mahasiswa harus melakukan presensi } \\
\text { setiap kali jadwal perkuliahan. Hal ini berfungsi sebagai } \\
\text { kontrol kehadiran. }\end{array}$ \\
\hline 4 & $\begin{array}{l}\text { Pengajar menyiapkan materi ajar yang akan disajikan dalam } \\
\text { kelas e-learning, baik berupa video maupun bentuk lainnya. }\end{array}$ \\
\hline 5 & $\begin{array}{l}\text { Pengajar menyajikan materi yang telah disiapkan ke dalam } \\
\text { kelas } \text { e-learning. }\end{array}$ \\
\hline 6 & $\begin{array}{l}\text { Untuk topik 1, Pendahuluan, pengajar menyajikan materi } \\
\text { dalam bentuk video. } \\
\text { Dipilih penyajian materi dalam bentuk video agar } \\
\text { penjelasan lebih leluasa disampaikan melalui audio dan } \\
\text { gambar. Materi bisa dalam bentuk apapun. } \\
\text { Untuk topik 2 - 5, pengajar menyajikan materi juga } \\
\text { masih dalam bentuk video. }\end{array}$ \\
\hline 7 & $\begin{array}{l}\text { Setelah materi di-upload ke dalam sistem e-learning, } \\
\text { pengajar mengatur restrict access untuk setiap materi dan sub } \\
\text { bagian materi (topik dan sub bagian topik). Maksudnya } \\
\text { adalah, pengajar men-setting terkait batasan akses untuk } \\
\text { setiap materi dan sub bagiannya. Dalam kegiatan ini, materi 1 }\end{array}$ \\
\hline
\end{tabular}

\begin{tabular}{|c|l|}
\hline & hanya dapat diakses jika mahasiswa telah membuka halaman \\
mengenai deskripsi mata kuliah. Dan setiap sub bagian materi \\
akan di-setting seperti demikian. Sub bagian materi hanya \\
dapat dibuka jika mahasiswa telah menyelesaikan sub bagian \\
sebelum-sebelumnya. Sehingga pengaksesan materi-materi \\
ajar yang telah di-upload ke dalam sistem -learning tidak \\
dapat dilakukan dengan melompat-lompatkan materi oleh \\
mahasiswa. Pengaksesan masing-masing materi hanya dapat \\
dilakukan terurut sesuai dengan urutan materi / topiknya \\
sebagaimana yang telah di-setting. \\
1 materi hanya diizinkan diakses pada hari pertemuan yang \\
sudah terjadwal.
\end{tabular}

Untuk metode unstructured learning, tidak diterapkan skenario khusus dalam penyajian konten pembelajarannya.

\section{B. Karakteristik Sampel Uji Coba}

Pemilihan partisipan yang diikutsertakan sebagai sampel dalam uji coba penelitian diperoleh melalui sebaran kuesioner di google form. Kuesioner berisikan beberapa pertanyaan terkait kebutuhan teknis saat pelaksanaan uji coba, seperti kepemilikan pc/laptop oleh calon partisipan, ketersediaan jaringan internet, platform yang digunakan, dan kemampuan partisipan dalam mengoperasikan suatu sistem. Diperoleh 34 partisipan yang memenuhi kriteria kebutuhan sampel penelitian, dimana partisipan merupakan mahasiswa dari Program Studi Sistem Informasi FST UNJA Angkatan 2019 sejumlah 9 orang dan 2020 sejumlah 25 orang. 


\section{Log Partisipan Dalam Aktivitas Pembelajaran}

Peneliti memanfaatkan fitur Log yang ada di menu LMS UNJA untuk memantau aktivitas pembelajaran kelas. Sehingga peneliti mengetahui siapa saja dan berapa jumlah mahasiswa yang masuk kelas dan mengakses materi per tiap hari-nya.

TABEL III

JUMLAH PARTISIPAN YANG MASUK KELAS DI TIAP PERTEMUAN

\begin{tabular}{|c|c|c|}
\hline \multirow{2}{*}{ Pertemuan Ke- } & \multicolumn{2}{|c|}{ Jumlah Partisipan Masuk Kelas (orang) } \\
\cline { 2 - 3 } & Structured Learning & $\begin{array}{c}\text { Unstructured } \\
\text { Learning }\end{array}$ \\
\hline 1 & 34 & 12 \\
\hline 2 & 34 & 9 \\
\hline 3 & 34 & 12 \\
\hline 4 & 34 & 12 \\
\hline 5 & 34 & 29 \\
\hline
\end{tabular}

Informasi di Tabel 2 diperoleh berdasarkan data histori Log yang diambil peneliti dari LMS UNJA. Data histori Log tersebut, selengkapnya dapat dilihat pada lampiran. Pada kelas structured learning, mahasiswa hanya bisa mengakses materi sesuai jadwal pertemuan, sehingga mahasiswa harus mengakses materi setiap kali jadwal pertemuan. Sedangkan pada kelas unstructured learning, mahasiswa diizinkan untuk mengakses dan menyelesaikan seluruh materi dalam 1 hari sekaligus atau pun tidak mengaksesnya sama sekali dalam satu hari atau lebih, jadwal akses materi bebas. Pada Tabel 2 terlihat hampir seluruh mahasiswa masuk ke kelas di pertemuan akhir, pertemuan ke-5.

\section{Evaluasi Hasil Uji Coba}

Tahapan selanjutnya adalah melakukan evaluasi kepada mahasiswa atas penyajian mata kuliah dengan dua metode pembelajaran berdasarkan hasil tes pemahaman materi. Hal ini dilakukan untuk melihat bagaimana pemahaman mahasiswa terhadap materi mata kuliah yang dibedakan atas dua kategori penyajian. Serta melakukan evaluasi kegunaan (usability) produk LMS UNJA.

\section{1) Evaluasi Aktivitas Pembelajaran}

Untuk mengevaluasi akhir dari aktivitas pembelajaran, peneliti melihat grafik nilai post-test akhir dari kedua kelas, seperti yang terlihat pada Gambar 1 dan 2. Tampak bahwa Gambar 1 mempunyai grafik nilai yang lebih baik daripada Gambar 2. Ini terbukti dengan rata-rata nilai post-test akhir kelas structured learning, yaitu 78,15. Sedangkan rata-rata nilai post-test akhir kelas unstructured learning, yaitu 69,19. Rendahnya nilai kelas unstructured learning, disebabkan partisipan yang tidak teratur dalam pengaksesan materi. Sebagian besar partisipan mengakses materi di batas akhir waktu, dengan materi yang menumpuk. Sehingga pembelajaran menjadi terburu-buru, dan ini mengakibatkan pemahaman materi menjadi berkurang karena kurang fokus akibat batas waktu. Berbeda dengan kelas structured learning yang mengharuskan partisipan menyelesaikan materi di hari yang sudah ditentukan, satu materi per satu hari. Dapat disimpulkan secara garis besar bahwa pembelajaran dengan metode structured learning mampu mengontrol kelas dengan baik sehingga memberikan hasil akhir yang baik terkait pemahaman materi pembelajaran.

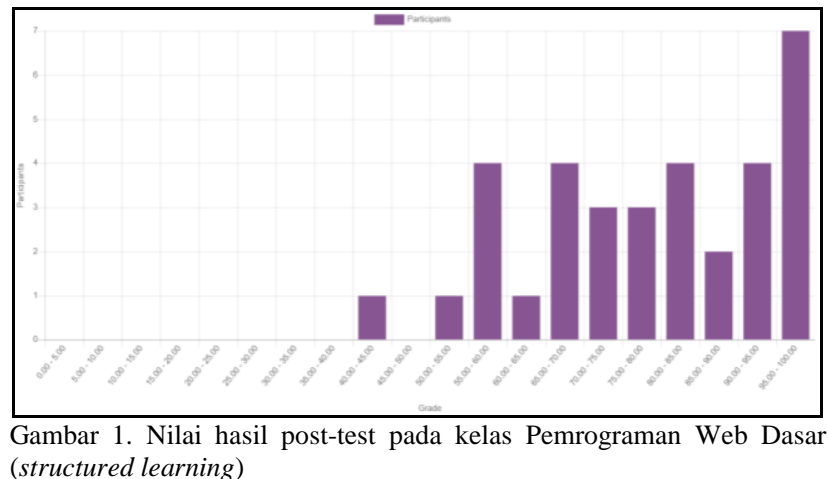
(structured learning)

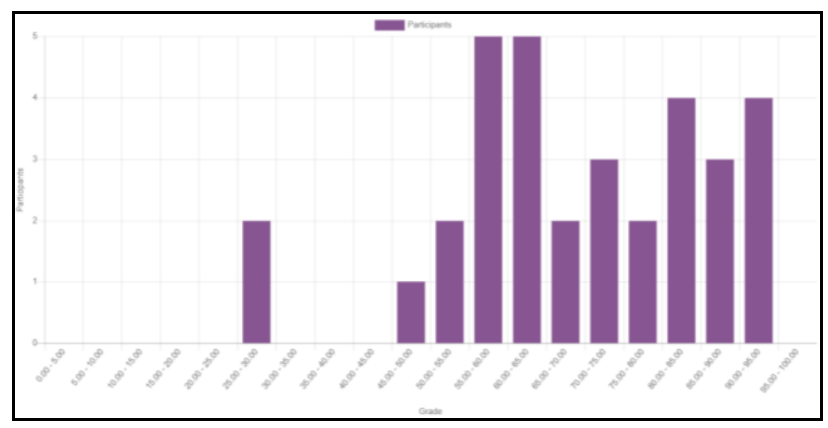

Gambar 2. Nilai hasil post-test pada kelas Basis Data I (unstructured learning)

\section{2) Evaluasi Usability LMS UNJA}

SUS (system usability scale) merupakan kuesioner untuk mengukur persepsi kegunaan. SUS berisi 10 pertanyaan dimana partisipan diberikan pilihan skala 1-5 untuk dijawab berdasarkan pada seberapa banyak mereka setuju dengan setiap pernyataan tersebut terhadap produk atau fitur yang diuji, dalam hal ini yaitu LMS UNJA. Nilai 1 berarti sangat tidak setuju dan 5 berarti sangat setuju dengan pernyataan tersebut. Bentuk-bentuk dari pertanyaan tersebut dapat dilihat pada lampiran. Tabel 3 berisi nilai respon partisipan terhadap 10 pertanyaan yang diajukan terkait kegunaan LMS UNJA, beserta SUS score yang diperoleh berdasarkan 10 pertanyaan yang diajukan tersebut. SUS score dihitung dengan aturan-aturan sebagai berikut:

a. Setiap pertanyaan bernomor ganjil, skor setiap pertanyaan yang didapat dari skor pengguna akan dikurangi 1.

b. Setiap pertanyaan bernomor genap, skor akhir didapat dari nilai 5 dikurangi skor pertanyaan yang didapat dari pengguna.

c. Skor SUS didapat dari hasil penjumlahan skor setiap pertanyaan yang kemudian dikali 2,5.

Selanjutnya, menghitung rata-rata skor SUS dengan menjumlahkan semua skor responden dan dibagi dengan jumlah responden. Berikut rumus menghitung skor SUS:

$x_{\text {rata }- \text { rata }}=\frac{\sum x}{n}$

Diperoleh rata-rata SUS score atas kegunaan produk LMS UNJA adalah 73,46. Terlihat jelas dari grafik 
persentase pada gambar 3 bahwa secara keseluruhan, produk LMS UNJA secara usability sudah dapat diterima atau sudah layak, sesuai dengan rata-rata SUS score yang diperoleh yaitu, 73,46 .

TABEL III

SUS SCORE
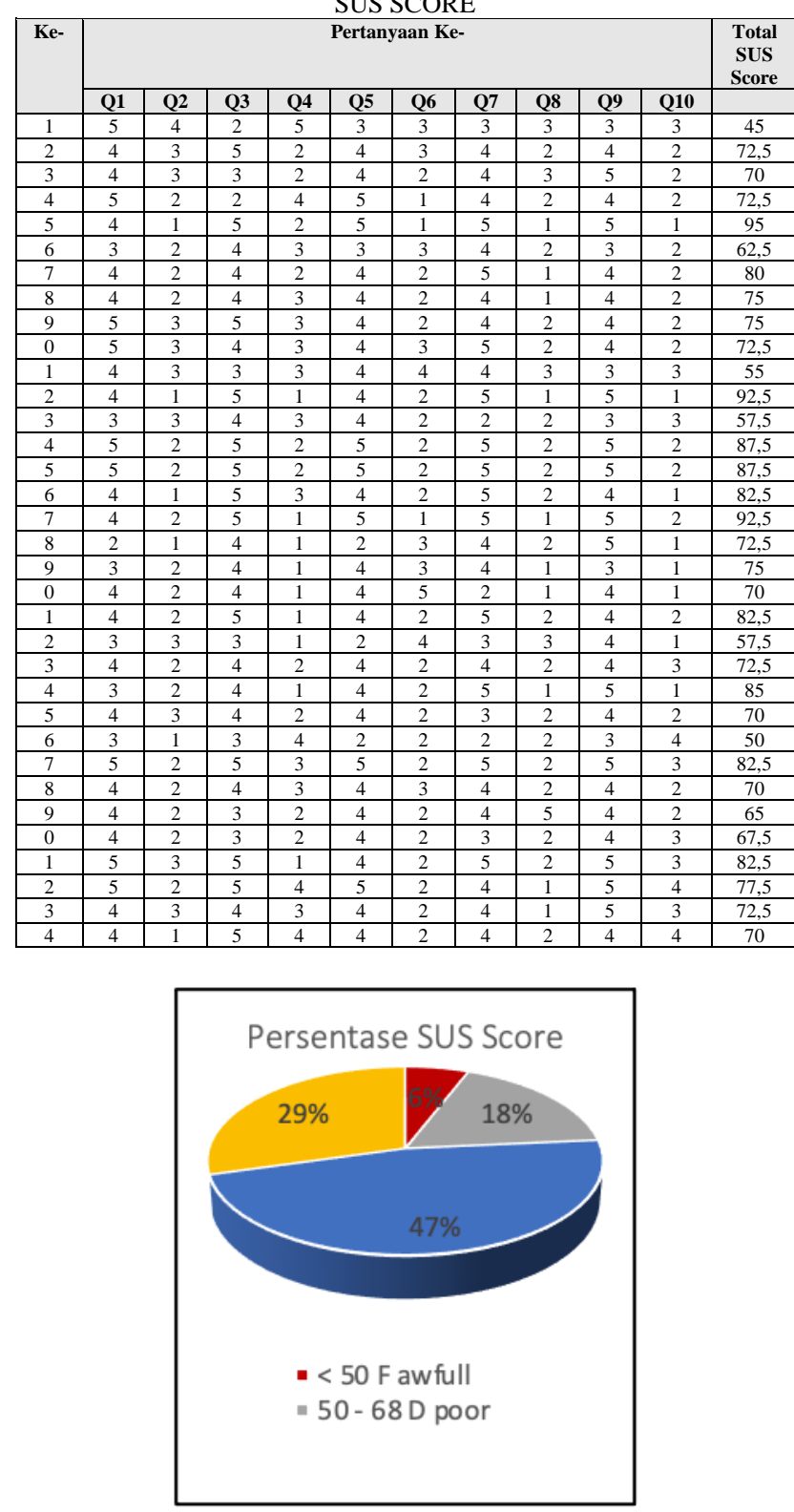

Gambar 3. Sebaran dan persentase SUS score

\section{KESIMPULAN}

Berdasarkan hasil penelitian, diperoleh kesimpulan, bahwa pembelajaran dengan metode structured learning mampu mengontrol kelas dengan baik sehingga memberikan hasil akhir yang baik terkait pemahaman materi pembelajaran dibandingkan dengan metode unstructured learning. Hal ini dibuktikan dengan nilai rata-rata post-test akhir 78,15 untuk metode structured learning dan 69,19 untuk metode unstructured learning.

Secara keseluruhan, produk LMS UNJA secara usability sudah dapat diterima atau sudah layak, sesuai dengan rata-rata nilai usability produk yang diperoleh yaitu, 73,46 .

\section{DAFTAR PUSTAKA}

D. Otto and S. Becker, "E-Learning and Sustainable Development," 2018, p. 8.

H. M. Selim, "Critical success factors for e-learning acceptance: Confirmatory factor models," Comput. Educ., 2007, doi: 10.1016/j.compedu.2005.09.004

[3] P. Nicholson, "A History of E-Learning," in Computers and Education, Dordrecht: Springer Netherlands, 2007, pp. 1-11.

[4] J. L. Moore, C. Dickson-Deane, and K. Galyen, "E-Learning, online learning, and distance learning environments: Are they the same?," Internet High. Educ., 2011, doi: 10.1016/j.iheduc.2010.10.001.

[5] I. P. Ramayasa, "Evaluation Model of Success and Acceptance of E-Learning," J. Theor. Appl. Inf. Technol., vol. 3182, no. 3, pp. 462-469, 2015, [Online]. Available: http://www.jatit.org/volumes/Vol82No3/16Vol82No3.pdf.

[6] D. Al-Fraihat, M. Joy, R. Masa'deh, and J. Sinclair, "Evaluating E-learning systems success: An empirical study," Comput. Human Behav., vol. 102, pp. 67-86, Jan. 2020, doi 10.1016/j.chb.2019.08.004

[7] R. E. Mayer, "Using multimedia for e-learning," Journal of Computer Assisted Learning. 2017, doi: 10.1111/jcal.12197.

[8] S. Choudhury and S. Pattnaik, "Emerging themes in e-learning: A review from the stakeholders' perspective," Comput. Educ., 2020, doi: 10.1016/j.compedu.2019.103657.

[9] M. W. Allen, Michael Allen's Guide to e-Learning. Hoboken, NJ, USA: John Wiley \& Sons, Inc., 2016.

[10] M. Johnson, "Effective practice with e-learning," Br. J. Educ. Technol., 2005, doi: 10.1111/j.1467-8535.2005.00547_5.x.

[11] Y.-H. Lee, C. Hsiao, and S. Hadi, "Enhancing e-learning Acceptance: An Empirical Examination on individual and system characteristics," Acad. Manag. Proc., vol. 2012, no. 1, p. 15828 , 2012, doi: $10.5465 / \mathrm{ambpp} .2012 .15828$ abstract.

[12] S. Ozkan and R. Koseler, "Multi-dimensional students' evaluation of e-learning systems in the higher education context: An empirical investigation," Comput. Educ., 2009, doi 10.1016/j.compedu.2009.06.011.

[13] C. De Medio, C. Limongelli, F. Sciarrone, and M. Temperini, "MoodleREC: A recommendation system for creating courses using the moodle e-learning platform," Comput. Human Behav., 2020, doi: 10.1016/j.chb.2019.106168.

[14] A. Revythi and N. Tselios, "Extension of Technology Acceptance Model by using System Usability Scale to assess behavioral intention to use e-learning," Educ. Inf. Technol., vol. 24, Jul. 2019, doi: 10.1007/s10639-019-09869-4.

[15] U. Ependi, F. Panjaitan, and H. Hutrianto, "System Usability Scale Antarmuka Palembang Guide Sebagai Media Pendukung Asian Games XVIII," J. Inf. Syst. Eng. Bus. Intell., vol. 3, no. 2, p. 80, 2017, doi: 10.20473/jisebi.3.2.80-86. 